\title{
Primary amyloidosis presenting intrahepatic cholestasis and fulminant hepatic failure
}

\author{
Ozturk Ates, ${ }^{1}$ Kemal Kosemehmetoglu, ${ }^{2}$ Gunes Guner, ${ }^{2}$ Yusuf Bayraktar ${ }^{3}$ \\ ${ }^{1}$ Department of Medical Oncology; ${ }^{2}$ Department of Pathology; ${ }^{3}$ Department of Gastroenterology, Hacettepe University, Ankara, \\ Turkey
}

\begin{abstract}
A 69-year-old man noticed abdominal pain located on right upper quadrant. Physical examination showed hepatosplenomegaly and icteric discoloration of sclera. On evaluation, patient was diagnosed to have hepatic amyloidosis related monoclonal gammopathy of undetermined significance (MGUS) and sinusoidal obstruction syndrome with intrahepatic cholestasis. In this case report we emphasize fulminant hepatic failure due to primer amyloidosis in diagnosed with MGUS patient.
\end{abstract}

\section{Introduction}

Amyloid is a fibrillar proteinaceous material that can be deposited in various tissues and may be resulted in a wide range of clinical manifestations. Amyloid is detected with Congo red staining. Several distinct types of amyloidosis have been classified such as amyloid light-chain (AL) (primary), serum amyloid A protein (AA) (secondary), dialysis related and senile amyloidosis. AL amyloidosis, caused by plasma cell dyscrasia, is due to deposition of protein derived from immunoglobulin light chain fragments. ${ }^{1}$ Liver is frequently involved by amyloid, but symptomatic involvement including rupture, portal hypertension or hepatic failure, is very rare. Cholestatic jaundice is an infrequent manifestation of amyloidosis and found in

Correspondence: Ozturk Ates, Department of Medical Oncology, Hacettepe University 06100, Sihhiye, Ankara, Turkey.

Tel.: +90.312.305.2929 - Fax: +90.312.305.5000.

E-mail: dr.ozturkates@yahoo.com

Key words: Fulminant hepatic failure; primary amyloidosis; intrahepatic cholestasis; monoclonal gammopathy of undetermined significance; sinusoidal obstruction syndrome.

Conflict of interest: the authors declare no potential conflict of interest.

Received for publication: 15 February 2015.

Revision received: 30 March 2015.

Accepted for publication: 3 April 2015.

This work is licensed under a Creative Commons Attribution NonCommercial 4.0 License (CC BY-NC 4.0).

CCopyright O. Ates et al., 2016

Licensee PAGEPress, Italy

Italian Journal of Medicine 2016; 10:71-73

doi:10.4081/itjm.2015.593 only approximately $5 \%$ of cases of amyloidosis., ${ }^{2,3}$ Monoclonal gammopathy of undetermined significance (MGUS) is an asymptomatic premalignant clonal plasma cell or lymphoplasmacytic proliferative disorder. MGUS related amyloid is very rare. ${ }^{4}$

\section{Case Report}

A 69-year-old man was admitted with abdominal pain located on right upper quadrant. He had also nausea, vomiting and weight loss of $15 \mathrm{~kg}$ in a year. He was diagnosed as having cholelithiasis and gastric ulcer. After medical treatment he had no improvement and then he was again admitted to hospital. There was neither family nor personal history of venous thrombosis nor exposure to drugs and hepatotoxic chemicals. A history of fifteen years of smoking and occasional alcohol consumption is noted. Clinical examination showed hepatosplenomegaly and icteric discoloration of sclera. There was no skeletal manifestation.

The laboratory findings were: hemoglobin level $13.6 \mathrm{~g} / \mathrm{dL}$ (13.6-17.2), leukocyte count 11,200 (4.3$\left.10.3 \times 10^{3}\right)$ hematocrit $38.5 \%(39.5-50.3)$, platelet count $389 \times 10^{3}\left(156-373 \times 10^{3}\right)$, erythrocyte sedimentation rate $47 \mathrm{~mm}(0-20)$, total bilirubin $3.07 \mathrm{mg} / \mathrm{dL}(0.1$ 1.2), alanine aminotransferase $58 \mathrm{IU} / \mathrm{L}$ (5-40), aspartate aminotransferase 79 IU/L (8-33), gamma glutamyl trans peptidase $2347 \mathrm{U} / \mathrm{L}$ (8-61), alkaline phosphatase 1752 U/L (35-129), cholesterol $271 \mathrm{mg} / \mathrm{dL}$, triglycerides $260 \mathrm{mg} / \mathrm{dL}$, low-density lipoproteins 206, albu$\min 3.8 \mathrm{~g} / \mathrm{dL}$ (3.5-4.3); prothrombin time international normalized ratio $1.27(0.75-1.5)$, activated partial thromboplastin time $28.7 \mathrm{~s}(25-40)$; CA19-9>1000 IU/L (0-39), iron 38, total iron binding capacity: 217 ug/dL (228-448), ferritin: $590 \mathrm{ng} / \mathrm{mL}$ (30-400). The 24-h urine protein loss was $0.613 \mathrm{~g} /$ day.

Serological tests were negative for hepatitis B, C and E, cytomegalovirus, Epstein-Barr virus and anti- 
nuclear, antimitochondrial, antiphospholipid and anticardiolipin antibodies. Protein C, S activity, antithrombin 3 activities, homocysteine level were normal. Prothrombin 20210A factor V Leiden, MTHFR mutations were negative. Immunoglobulin (Ig) G 1310 mg/dL (751-1560), IgA 224 mg/dL (82453), IgM $67.8 \mathrm{mg} / \mathrm{dL}$ (46-304). Serum immune electrophoresis showed decreased albumin, $\alpha-1$ and $\alpha-2$, increased gamma band. Urinary immune electrophoresis showed non-selective proteinuria. Serum $\lambda$ and $\kappa$ light chain were $>277 \mathrm{mg} / \mathrm{dL}(5.7-26.1)$ and 28.4 $\mathrm{mg} / \mathrm{dL}$ (3.3-19.4), respectively. Urinary free light chain $\kappa$ is $28.8 \mathrm{mg} / \mathrm{dL}(0.39-15)$. Abdominal ultrasonography and abdominal tomography revealed hepatomegaly and splenomegaly without evidence of space-occupying lesions, no dilated bile ducts. Echocardiography showed with no sign of right heart failure.

Portal and hepatic venous Doppler ultrasonography, by using Siemens Antares ${ }^{\mathrm{TM}}$ (Siemens AG, Monaco, Germany), revealed enlarged congested liver and the absence of portal vein thrombosis. Portal vein was $8.5 \mathrm{~mm}$ in a diameter with hepatopetal blood flow. Esophagogastroduodenoscopy showed antral gastritis and there were no varices. Histological examination of biopsy revealed chronic atrophic gastritis with accompanying focal amyloid deposition on vessel walls. Fiber sigmoidoscopy was normal and rectal biopsy showed no amyloid deposition. Liver biopsy specimen revealed marked diffuse, amorphous, eosinophilic deposition in perisinusoidal liver parenchyma obliterating normal liver architecture (Figure 1A). This amorphous material had the staining characteristics of amyloid with Congo red and immune histochemically amyloid P (Figure 1B and C). Further immune histochemical investigation of amyloid resulted in AL amyloidosis with strong $\lambda$ staining compared to $\kappa$ (Figure $1 \mathrm{E}$ and F). Amyloid A, apoA1, fibrinogen, lysozyme and transthyretin were negative. This deposition of amyloid caused atrophy of hepatocytes and narrowing of sinusoids. Subsequent bone morrow biopsy showed an increase in plasma cell count (8-10\%) some displaying atypical features (Figure 2) and amyloid was also encountered in stromal and vessel walls. He had been diagnosed as AL amyloidosis with MGUS. At the course of disease bilirubin level greatly increased up to $24.5 \mathrm{mg} / \mathrm{dL}$. There was no improvement in clinical findings and patient died after 3 months of diagnosis.
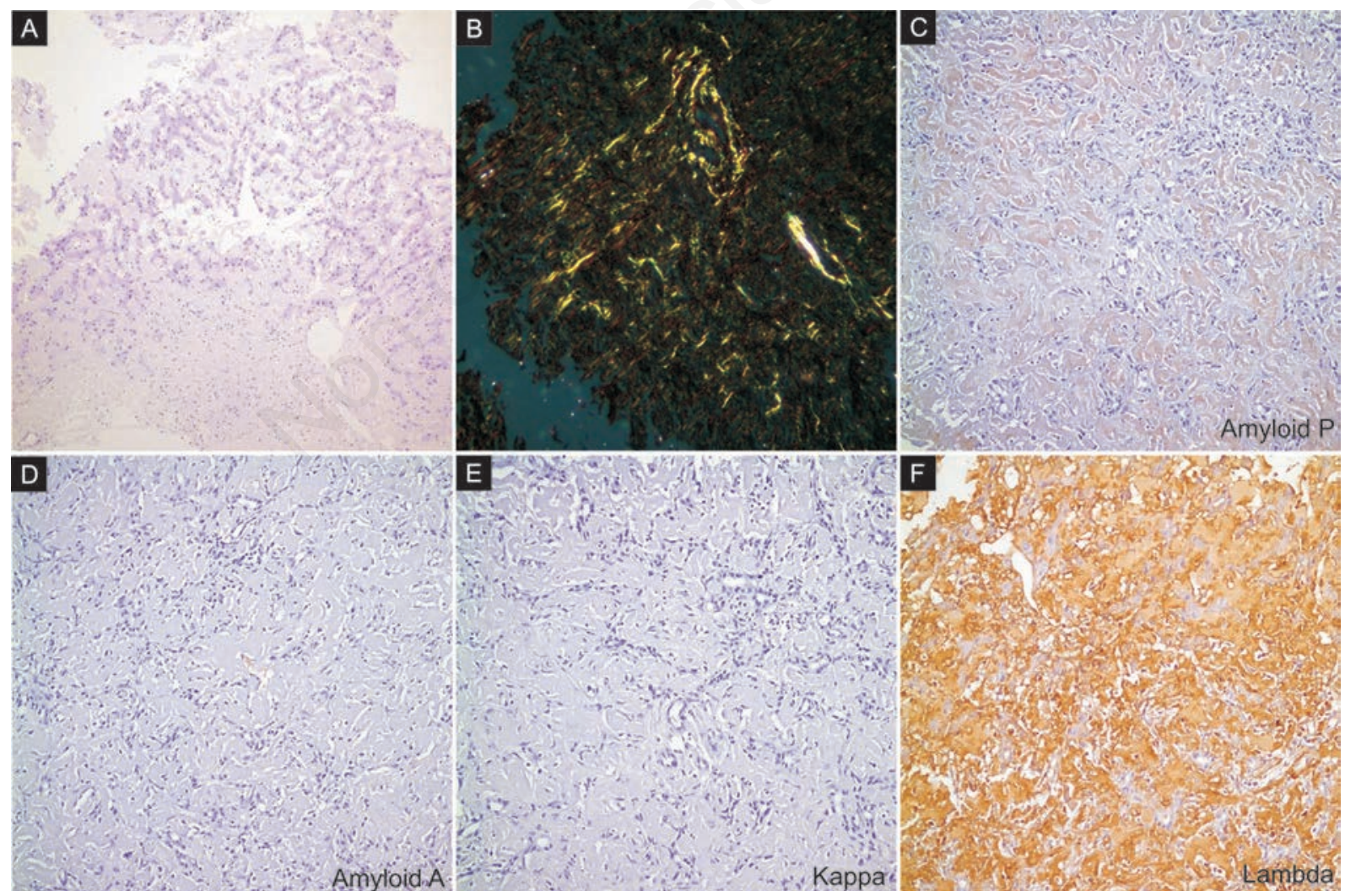

Figure 1. A) Massifs eozonophilic amorphous extracellular accumulation of amyloid obliterating normal liver structure; B) Congo red staining on polarized light revealed characteristic bright yellowish green birefringence; C) Amyloid P protein was also positive, sinusoidal amyloid deposition was strongly positive with $\lambda(F)$ in contrast to $\kappa(E)$ and amyloid $A$ protein (D) both of which were negative (A: 100x H\&E; B: Congo red 200x; C-F: 200x). 


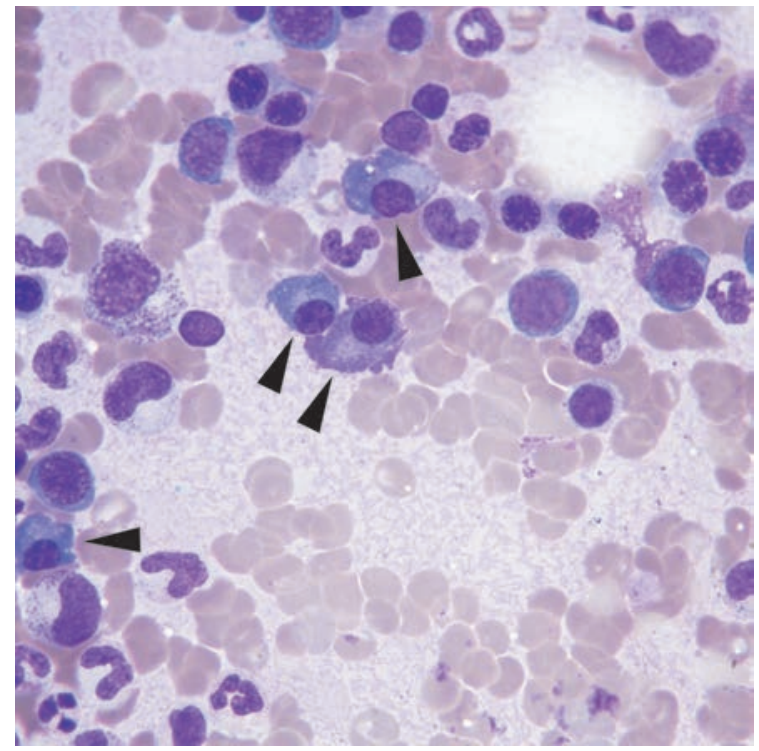

Figure 2. Increased plasma cells on bone marrow aspiration smear (Giemsa $x 400$ ). mild increased portal pressure. Cholestasis is encountered in 5\% of cases during the course of disease and elevation in liver enzymes especially alkaline phosphatase (ALP), gamma-glutamyl transferase (GGT) is detected. ${ }^{2,6}$ Large quantities of amyloid are deposited between sinusoidal wall in the space of Disse and columns of liver cells interfere with bile and blood flow giving the appearance of cholestatic jaundice, which occurred in our case. In whom had major increase in ALP and GGT but bilirubin level was slightly elevated. Subsequently increasing of bilirubin has become greater than ALP and GGT, which can be as a result of obstructive cholestasis. Intense amyloid deposition is interfering with bile passage into the bile canaliculi and small bile ducts.

Cardiac involvement is the most common cause of death in AL amyloidosis. Edema and ascites may be related to decreased albumin due to nephrotic syndrome or cardiac failure. In our patient there was neither ascites nor esophageal varices in upper endoscopy; serum albumin level and heart function were normal in our patient.

\section{Conclusions}

In conclusion we should take into consideration the systemic amyloidosis patients showing high cholestatic enzyme because they may have hepatic amyloidosis.

\section{References}

1. Falk RH, Skinner M. The systemic amyloidosis: an overview. Adv Intern Med 2000;45:107-37.

2. Peters RA, Koukoulis G, Gimson A. Primary amyloidosis and severe intrahepatic cholestatic jaundice. Gut 1994;35:1322-5.

3. Melkebeke P, Vandepitte J, Hannon R, Fevery J. Huge hepatomegaly, jaundice and portal hypertension due to amyloidosis of the liver. Digestion 1980;20:351-7.

4. Katayama Y, Sakai A, Nobuyoshi M, et al. Detection of monoclonal plasma cells in bone marrow and spleen of primary amyloidosis. Rinsho Ketsueki 2001;42:705-9.

5. Gertz MA, Kyle RA. Hepatic amyloidosis (Primary AL, immunoglobulin light chain): the natural history in 80 patients. Am J Med 1988;85:73-80.

6. Culafic D, Perisic M, Ivan Boricic I, et al. Primary amyloidosis presenting with cholestasis and hyperkinetic portal hypertension. J Gastrointestinal Liver Dis 2007; 16:201-4 